\title{
Study the position of woman in the works of three contemporary Iranian painters with a feminist approach
}

\author{
Narsis Rafati ${ }^{1 *}$ Parvaneh Danesh ${ }^{2 *}$ Sara Khiabanian ${ }^{3 *}$ \\ 1. Narsis Rafati, Faculty of Civil, Art and Architecture of Islamic Azad University, Science and Research \\ Branch, Tehran, Hesarak, Tehran,Iran, PO box 1477893855 \\ 2. Parvaneh Danesh (Associate Professor), Payame Noor University, Western Tehran Branch, Shahrak \\ Shahid Bagheri, Kharazi Highway, Tehran,Iran, PO: 1495933399 \\ 3. Sara Khiabanian, Faculty of Civil, Art and Architecture of Islamic Azad University, Science and \\ Research Branch, Tehran, Hesarak, Tehran,Iran, PO box 1477893855
}

\begin{abstract}
Today, by various and diverse approaches in the artistic critique and analysis, different aspects of sociological concepts and trends can be deduced from artistic works. Feminism and its different approaches can also be effective and successful in understanding and revealing some of the concepts related to the art. Feminist art in the contemporary world can have media function as a method and means for expressing the female-oriented demands and views. In the current society of Iran, painting as a collection of tendencies and different perspectives has female-oriented and feminist concepts in itself. This research, by studying the works of three painters (Shideh Tami, Saeed Rafiee Monfared, Zeinab Movahhed) seeks to follow represented position of the woman in the works and determined how each of these artists in her or his painting deals with the issue of woman, her role and her picture. The research is conducted by descriptive-analytical method. The method of collecting research data was field and library-documentary and questionnaire and interviews were used for this process. This study implies that every painter with a personal way was involved with the issue of woman in his/her work and each of them used this concept in their works in terms of their own thinking and personal attitude. The works of these painters have been avoided from a sexism view as far as possible; but the arrangement of this view is seen in the works of these painters i.e. Zeinab Movahhed, Saeed Rafiee Monfared and Shideh Tami.
\end{abstract}

Keywords: Woman, female-oriented, Feminism, contemporary painting of Iran, feminist art

DOI: $10.7176 / \mathrm{ADS} / 73-04$

Publication date:May $31^{\text {st }} 2019$

\section{Introduction}

Art can also be presented as a form of creation and as a form of recognition; the latter is used more in the sociology of art. In this view, art as science is a way for recognition; but if the science tool is wisdom in the path of cognition, the second view determines the way of art recognition as affection and intuition. Recognition is formed in the three levels of discovery, expression and acceptance by the audience. According to this definition, the artist achieves a certain awareness (for example, the beauty of a phenomenon), then manifests it as an artistic manner and in a particular art; in the next stage, this work is accepted by an artistic audience. Regarding to such a statement, art can be analysed in a communication framework. Sociology of art is one of the sociological fields, which includes several study axes. These axes include study of artists, artistic works and finally cultural and artistic policies. Study in the axis of artists, forms the subdomain of sociology of the artists. On the other hand, the concept of feminism is a part of other originality and shows itself in the various domains such as race, ethnicity and gender and the women originality movement are the most controversial of it. The sociology of painting is intended to provide sociological analysis of painting as a system, including: One can start with the creator of the work and the position he has in the community or from the consumers and users of any artwork and their distribution in the socio-economic hierarchy of the community, or from the institutions that have influenced the creation of the artwork or even from considering the institutions that the creator of the work can be found in their foundation. Also, the sociology of painting considers the impact of social constraints on the 
The woman is a subject that always plays a key role in the art arenas, especially the painting arena. The way women are represented in these works at different times, were influenced by the cultural parameters prevailed at that time and due to it, we face various pictures of women in the paintings in different times. So that in West, woman is proposed merely as a model and the theme of painting and it is a reflection of male view (the painter) to the female (painting theme).

The 1970s were the years of relation change among women, literature and art. The feminists of the second half of 20th century fought to the "woman of picture" or woman as a reflection of imagination and tendency of a man and some of female artists were trying to provide a "feminine art". In these years, the new women's movement was formed, a movement whose goal was no longer merely a struggle against inequalities, but an attempt to show women's differences in the arena of art. The movement, which is called counterculture movement or is known as a tendency to anti-aesthetics, emphasized on the differences and characteristics of feminine art.

Feminists believe that there is a huge difference between the works of male and female painters in illustrating the woman. Male painters portray mostly imaginary pictures of woman in a mythical and lyrical atmosphere; they ignore the true presence of woman and portray women as their own desire. While female painters do not portray themselves as legendary and ideal human beings, but they try to ruin expected stereotypes of woman by using some strategies and create a new picture of woman.

Woman in the Iranian culture has always enjoyed a graceful position and status. One of the indicators of intellectual and social development of societies is the kind of their view to the women, which has always had a special place in the Iranian culture. Although this process has experienced ups and downs due to the incursions and eclectic cultures which emerged in periods of time, but the general spirit of Iranian culture is the celebration and glorification of woman and this issue can be seen in Iranian literature and art. Since the painting reflects the believes of the artist and the artist takes his believes and thoughts from society and returns to it; so, this research seeks to realize the kind of attitude toward the woman's social position in the painting of contemporary artists and also to find the relation of this attitude with gender of the painters. Ultimately, the research wants to answer the question that: How far the painting of studied painters was successful in representing the actual role of women?

\section{Methodology}

This research, based on the purpose and type of the data, is expanding type, and by reviewing its findings, which are derived from library and field studies and through interview, answers to the questions and the outcome of this review is the analysis of works of the artists who were concerned by the research. The statistical population of the study is based on the study of feminist tendencies in the contemporary painting of Iran that includes all contemporary painters who have used the role and image of woman in their works. Since the items that can propose in the statistical population are very large in number and also the qualitative and quantitative conditions and the intended indicators are not identical among all the works; inevitably, the selection method or improbable examples are used. In the section of introducing statistical population, twenty works of three painters studied by research are described and analysed as case study. These three painters are: Shideh Tami, Saeed Rafiee Monfared and Zeinab Movahhed. In this article, from each painter, three more important works are considered for presentation.

The tool used in this research is a questionnaire for interviewing the discussed artists. In fact, in the practical dimension, semi-structured interviews are conducted and the tools which are used in the present research are observation, interviews and telephone interviews in order to complete the interview process and to resolve the defects of interviews. For analysing the data, descriptive-analytical method has been used. In this method, after describing the appearance of the work, its internal relations and content are analysed, and finally after the interpretation, the intended work is evaluated.

\section{Research history}

Bahar Arbabi (2014) in a research entitled as "the analysis of the social reflection of a woman's picture in the Iranian paintings of 2000s" studied the relation between proposed image of women in the paintings of 2000s and women in the today's Iran. The above research is fundamental in terms of purpose and its method is descriptiveanalytics. Also, in this research, globalization and reflection approach as theoretical frameworks are used to 
analyse the contents and artworks. According to the findings of research, it is concluded that the art of Iranian painting in 2000s, with all the issues that have existed in the artistic atmosphere of this decade, including issues related to the art market and the fashion industry, expresses some of the issues related to the women of Iranian society. The artists have used a variety of approaches to express the facts before women in the society and, in many cases, have criticized the status and issues of women in Iranian society. Nastaran Afshar (2011) in a study entitled as "investigating women portrait in the contemporary painting", believes that, in fact, the picture itself is a kind of biography and the registration of the artist's perception from himself, and in the last century, considering the role of woman in various fields, including trade, politics, work, art, ... and the formation of new movements and the emergence of female artists; women, like men desire to portray themselves. The mentioned research is conducted by descriptive-analytical and library method and its purpose is to represent the faces in the painter's personal works and showing the presence of sharing in the portrait in recent times and considering the feminine identity of the painter in creating the work. Zohre Abbasi Shakibapour (2014) in a research entitled as "the analysis of representing woman's position in the paintings of Qajar" (a case study on the first half of 1795 to 1847), represents woman's position in the works of first half of Qajar and refers to the fact that representing women in the first half painting is formed based on which components and how far the women that are portrayed in these paintings have personality character. This research has been carried out through a descriptive-analytical and library method and this concluded that the domination of the thought and culture of masculism considers the woman to be inherently defective and weak. The consequence of this idea was "Gynophobia" which led to deprivation of women from their most natural social rights and put women away from their real position. Qajar officials mostly cared about beauty of women and this can be seen well in the first half paintings of Qajar that portrayed women on the desire of Qajar men. Amir Alikhani Rad in a research (2009) entitled as "the picture of woman in the paintings of Iran and west" (second half of the twentieth century), investigates the works of contemporary Iranian and western artists in the second half of the twentieth century in order to find out how they look at the woman picture in the works of painters of this time; and to analyse currents of thought and kind of attitude of these works from the changes and the approach of their background. This research is formed based on written and visual sources and has been accomplished in two general ways: 1- historical and 2-subject-oriented. According the result of this research, the image of woman as a migratory in various historical and social contexts can help us in their deeper understanding.

\section{Thematic literature}

\subsection{Feminism}

What comes to one's mind by hearing the words "feminism" is that's its associated with women, with an aim to raise their social status as equal to men. It supports women's right and wants them to achieve a balanced status as men. "Feminism is a belief that women and men are inherently of equal worth. Because most societies privilege men as a group, social movements are necessary to achieve equality between women and men, with the understanding that gender always intersects with other social hierarchies" (Freedman, 2007)

\section{2: Feminism Approaches}

Feminism can be arranged in two general approaches, and on this basis, a more precise image of it can be described. The types of feminism can be reviewed based on these two general approaches. One of these approaches is descriptive in which the orientation of all feminist debates is in such a way that women are considered as real and existing subjects or issues. The second approach is a normative that views women as they should be and deserve. These two (normative and descriptive) approaches have become the origin of the transforming the way of viewing women and changing the ways of attitude at the subject of women's identity; as advocates of feminism not only emphasize on the normative aspects (must) of women's identities and analyse the present situation of women (descriptive), but also continue their struggles in this regard (Sajjadi 2005).

\section{3: Art and Feminism}

Aesthetics denotes the philosophy of art or of a specific medium. Feminist interventions in aesthetics account for the historical absence of women from the canons of creative disciplines; recover and revalue the work of women artists; critique theoretical structures that devalue the feminine or exclude female producers; and propose alternative aesthetics that centralize female subjectivity or highlight the role of gender in art. (Encyclopedia of Feminist Literary Theory)

What feminist artists do share is a sense of the historic social subordination of women and an awareness of how 
art practices have perpetuated that subordination. That perpetuation has been accomplished by such things as ignoring women's work, objectifying women's bodies in painting and film, romanticizing the sexual exploitation of women in narrative, employing exclusionary criteria for women's creativity or carrying on the symbolic system that regard the feminine as dark rival to masculine. (Korsmeyer,2004)

Feminist discourse on aesthetics arose in the 1970s out of the women's movement. Farreaching early propositions were that women's artistic productions do not fit into the existing categories of art history; that art history as traditionally constituted applies mainly to male experience; and that aesthetics needs to be set in a social history of gender. Feminists sketched out a progress of women's art from household crafts to artworks with liberatory social messages. Feminist artists and critics have worked in popular media such as science fiction and rock music as well as in the fine arts. In visual art, feminist artists have transformed the American and European art worlds since 1970. (Encyclopedia of Feminist Literary Theory)

\section{4.: Woman as creator of artwork}

Feminists believe that women, as creators of artworks have been less recognized in the history. They believe that this lack of appearance is not related to decrease of women's ability and talent, but the intellectual and social conditions of society has been in such a way which has not given the opportunity for the manifestation of artistic talents to women. Feminists are trying to show that history of art is not neutral, but male gender has always been considered an absolute symbol; women are deprived of artistic creation in the shadow of this idea. Basically, the aesthetic approach of feminism is a postmodernist attitude.

The theory of postmodernism more confronted with the sense of authoritarian integration or globalization of modernism and the character which tried to impose the single reading and legitimated the other readings too. Understanding this feature of postmodernism is the key to understand the feminist thought; i.e. the understanding the commitment that modernism seeks not to look at others and these others may be "non-western" non-men "or" non-white peoples ".

The first efforts made by postmodernism were to pay more attention to other views; i.e. non-Western, nonEuropean and women as well. (Sami-Azar, 2007)

\subsection{1.: To distort the meaning of genius}

While the concept of genius has classical origins, it has undergone many twists and turns in the history of art and philosophy. The eighteenth century and the Romantic movement promoted a particularly powerful role for genius and fostered the cult of the individual man of exceptional capacities who gives less gifted artists the tools to create. In Kant's famous words: "Genius is the talent that gives the rule to art." During this period, moreover, genius was ferociously guarded as a male preserve.

Metaphors of labour and birth popularly describe artistic inspiration and creation, for example. Both masculine traits (toughness, courage) and feminine ones (emotional sensitivity) are interpreted as having special creative powers and are assigned to the best minds of an age, minds with virtually exclusively male exemplars.

Genius does not describe males in general contrast to females, because the world produces few geniuses at all. This term is reserved for the select number of creators who have not only produced superior artworks, but whose vision has altered the direction of the field altogether. As Kant put it, the genius opens paths for artists of lesser accomplishment to follow, whether they be male or female. (Korsmeyer,2004).

Feminists believe that the concept of "ingenuity", although throughout its long history, has observed a variety of forms, but in none of them, the genius of women can't be found. Ingenuity for its creativity and bold initiative, and due to ability of creative artist to promote what nature or culture has given, has remained in the realm of men. On the other hand, small number of women who have a place in their artistic history like a man, have strengthened the belief that the minds of women are not able to make innovation and ingenuity. (Ataei Ashtiani, 2006).

\section{5: Women as observers of artwork}

Feminists believe that the traditional flow of art history not only did not pay attention to the creativity of women in creation of artworks, but also did not value aesthetic perception of women as an observer. While, in the light of extensive researches and studies by anthropologists and psychologists, relative supremacy of the right hemisphere of women's brain has been admitted that has a great influence on critique and opinion, especially in the aesthetic aspects of artwork but also there is a male view in this field. Of course, this dominance of the 
masculine prospect on the one hand, is the cause of not valuing feminine view in artistic productions, and on the other hand has led to a significant lack of women in art field. Feminists have presented "male gaze theory" to explain the disregard of women's view as an artwork observer. (Bolkhari, 2010).

\subsection{1: Male gaze theory}

Analysis of vision and of what has become known as "the male gaze "presume that the ability to look at others is an indication of sexual and social power. Theories of the gaze stress the activity of vision, its mastery and control of the aesthetic object. These theories reject the separation of desire from pleasure, reinstating the erotic, covetous gaze into the core of beauty. (Korsmeyer, 2004)

Theories of the gaze also challenge the presumption that the model audience for art is a universal, generic spectator, noting the potential disruption of appreciation at those times when the point of view prescribed by the object does not conform with the subject position of the viewer. To say that an "imaginative position "is prescribed means that the artwork directs the viewer to regard the work in a particular way, that is, specifically in a way that privileges a masculine spectator as the authoritative viewer of art and judge of its quality. (Miller,1997).

The result of this theory, relying on the interpretation of artistic objects obtained from painting and nudity of Hollywood films, suggests that the image of a woman in art was often intended to transform her into an object. Here, the man has an audience role. Feminists believe that this superiority of male look can be seen more clearly in sexy movies and Hollywood productions. In these productions, women are interesting subjects and men have more active role in visual arts because they own the look. In their view, relations governing the separation of power are appeared only by the look; in fact, method used in artworks in the form of words or painting is directed by the external observer. (Ataee Ashtiani,2006)

\section{6: Woman as subject of art}

One of the foci of early feminist art streams was the visual representation of the female body-generally nude-in painting, sculpture and photography. In similar fashion to feminist performance art, the artist who addressed this issue presented their own bodies in unprecedented forms-being immersed, wrapped, submitted to mystical rituals, and photographed in various experiential poses-to convey their message from an intensely personal perspective, this physical corporeality serving them as both creative material and canvas. Like the feminist philosophers of the 1970s, these feminist artists set out to change the prevalent image of female body, protesting its idealisation by patriarchal society and the distortion of its true beauty, sensuality, desires and passion. (Dekel 2013)

\subsection{1: Showing female body and creating hate}

One of the methods in which artists of second-wave feminists tried to attract the attention of community to subordinate position of women in the art history was to show their body. Feminist artists made every effort in their artworks to break taboos that indicate sexual differences, such as menstruation and childbirth, and widely used woman' body images in their works. Of course, their purpose was not to create more grounds for men to enjoy, but they believed that art should provoke hatred in observer instead of satisfying taste and pleasure of male toward to women's body. They consider the creation of hatred as a kind of aesthetic, and they believed that hatred like an aesthetic reaction, which provides various meanings for the audience, changes the political, social and ethical meanings. They believed hatred, in addition to creating an artistic innovation, has two political meanings: first, it challenges the ideal and arbitrary female revers state that has been made by men: such as beauty and adornment, tiny and neatness and being tempting and against these expectations draw or show bodies that are not consistent with standards. These complex works reversed traditional aesthetic values that were expected to be seen in the naked body. Second, it creates an annoying emotional effect that make the observer to question its values (Korsmeyer, 2004),

\section{Research findings}

In this section, by addressing the painting works of desired artists in the research (Saeed Rafiee Monfared, Shideh Tami and Zeinab Movahhed) the various approaches of these three artists with the image of the woman are being studied in order to evaluate their mental and visual meaning and references.

\subsection{Shideh Tami}

Shideh Tami was born in Tehran in 1962. She was interested in literature from the childhood and wrote poetry. In 
high school, she chose empirical science, received diploma but gradually became more interested in art. In 1983, at the suggestion of one of her friends, she took part in Aydin Aghdashlo's classes for a short time. At the same time, by pursuance of Aydin Aghdashloo in 1987, she published her first poetry book entitled "The Serum of the Night". In addition to poetry, figurative painting became one of her main concerns. Eventually in 1992, she held her first exhibition of self-portraits, and professionally entered the world of art. Since then, the face and body of human becomes a major and repetitive subject in the works of Shideh Tami. Only in the mid-nineties, after the death of her close friend, the role of human was removed from her paintings and up to two years painted empty seats. She is a self-taught artist that during her artistic career always tried to eliminate academic limitations, breaks the shell and physical appearance of humans and directly express mental and psychological complexities of human beings.

This artist does not consider woman as the second gender and mind her as a human being. In the works of her, this matter is clearly visible. Although she benefited more from the images of women in her work, but it is not possible to give critical and women-oriented sight on these works because the woman is only meaningful with her presence in her works and particular approach cannot be found in these works. In any case, she portrays the faces that, at first glance it is difficult to distinguish them from the man, even though did not essentially intended gender for them.

Tami sometimes uses a variety of techniques to express his feelings, which in a conceptual expression ends in his favour. She has used Collage technique well in some of her works, so she has created a different atmosphere. In one of her works, Tami painted a portrait that may be a portrait of herself This personal portrait displays a woman's face most of which contains warm colours surrounded by collages of a classic sculpture. It has given a sort of suspension and nudity to the masculine body. The stunned look of a woman in this picture is interesting. The cool colour theme which created the various pieces of the body around the frame, in addition to creating a colour contrast, creates a sense of non-impressionable feeling in the face frame which is similar to the hair. The deliberate clumsy of the painter in Expressionist colouring on the skin of face, wounds and his injured skin further provokes the person. Perhaps the presence of an indifferent, rigid and inanimate, though handsome who has been suspended around the woman, has been the painter's intention or the woman's strangeness and astonishment are due to an unfamiliar element (Figure 1).

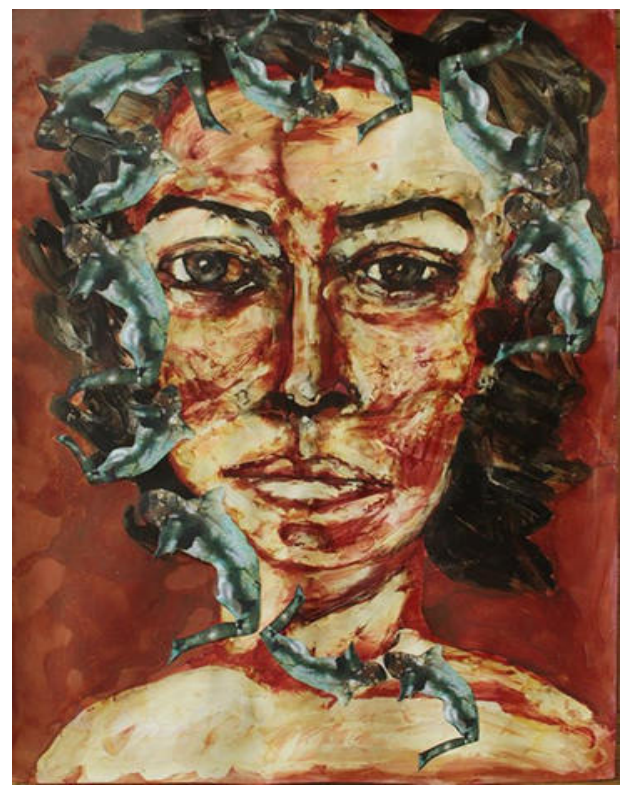

Figure 1. Untitled, the work of Tami, Acrylic and Collage on paper

Tami sometimes benefited from variety of techniques to express her feelings, which ends in the conceptual expression in her favour. She has used Collage technique well in some of her works and that created different atmosphere for this reason. In the below work, she painted a portrait that it is maybe a portrait from herself. This personal portrait displays a woman's face often with the warm colours that surrounded by collages of a classic sculpture image. It has given a state of suspense and weightlessness to the men's figure. The startled look of the 
woman in this picture is interesting.

The cool colour theme made various pieces of the figure around the frame, in addition to contrasting colours, the hair in the face frame creates a sense of non-impressionable existence. The deliberate inexperience of the painter in expressionistic impasto on the skin of face also, further induces individual's wounds and injured skin. Perhaps the presence of an indifferent and lifeless but handsome man, who was suspended around the woman was the meant of painter or woman's confusion and astonishment is characterized by an unfamiliar element.

The expressionistic view accompanied by violence in impasto of Shideh Tami drives her works into the concepts of human suffering realm. From the same kind of suffering that affected women everywhere around the world over some years. The expression of these cases that also interested by feminists can create feminist and protesting painting. Nevertheless, what the artist herself acknowledges is contrary to this, she only develops her inner feelings, regardless of the patriarchal or political system governing work communities. The expression of hidden image into the Shideh Tami's works is the result of her inner states and emotional feeling of her social life. However, among them may also mention the political or civilian influences.

This kind of Expressionist expression is also reflecting in the design of her works. Deforming and formlessness faces that Tami portrays can be considered as the one of her main work characteristics and counted as signature and fingerprint. Of course, this kind of visual expression in its nature hides messages from human suffer or contemporary man's identity, but she paints with no direct attention to this type of estates and portraits her influences from society indirectly and in an expressive way. In some of her works, she leads the colourlessness and designing expression of this case towards the some unpleasant emotions. Daily grieves that surrounds the contemporary man (Figure 2).

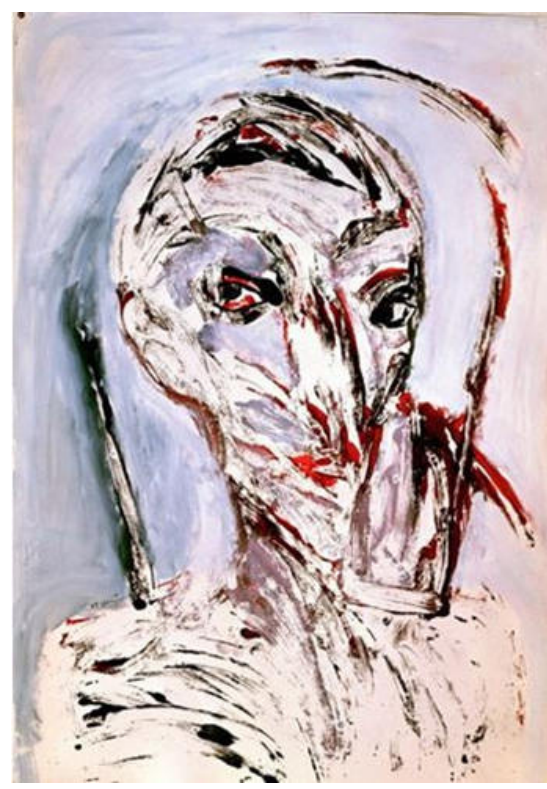

Figure (2) untitled, by Shideh Tami, Acrylic on Canvas

She often draws promptly and immediately. It can be said that in a collection called Jazr-o-madd (Tide), she painted with more inner logic and wisdom. In this collection, which consists of two parts, she displays two images of a subject. In a number of the works in this collection, an image has been created positively and negatively (the upper part is positive, and the lower part is negative). In this collection, she used the design media rather than in the rest of her works. Through the design and the use of a digital tool (positive and negative images), she created a collection that has the greatest distances with herself and her other periodic works. In this collection, using digital knowledge, in the lower part, she created the negative or inverse image of every image that she created normally. In these images, Tami's main subject has also been portraiture, especially portraiture of women, which, using several elements, symbols or other images narrates. Avoiding any offhand idea and any acting sensation, she has designed her work and by logically setting the picks, she has created her painting. In any case, intentionally or unintentionally, Shideh Tami shows her inner thoughts, emotions and feelings by having a woman-oriented look (Figure 3). 


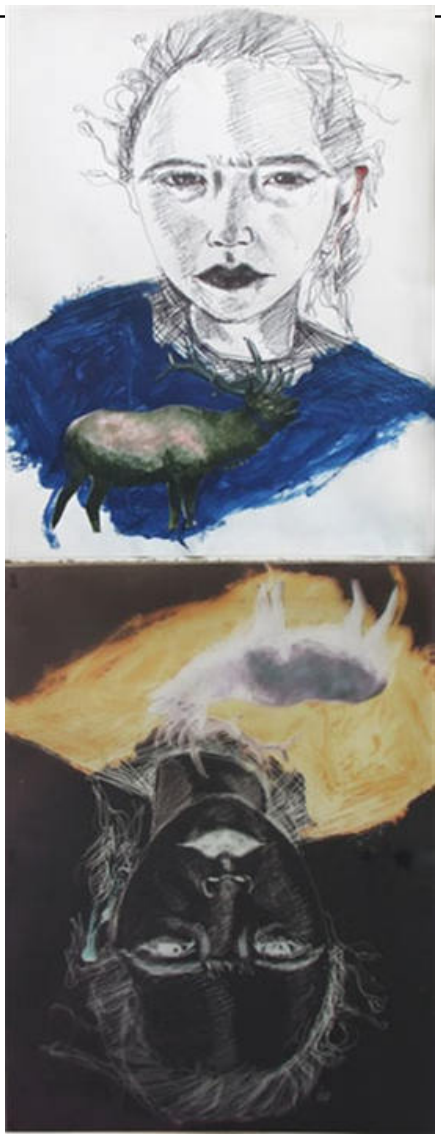

Figure3. Untitled, From Jazr-o-madd (tide) Collection, Shideh Tami's work, a combination of materials on paper, 2017

\subsection{Saeed Rafiee Monfared}

Saeed Rafiee Monfared was born in Tehran in 1971. He holds the B.A in Fine Art from Islamic Azad University as well as associate member of the Iranian Painters Association and an honorary member of the Visual Arts Development Institute. He was abandoned his education unfinished in the master's degree of Fine Art in University. In addition to painting also wrote critic for film and cinema and printed caricature for publications. He has teaching experience at several universities, in different degrees and numerous educational centres. He has individual and group exhibitions both inside and outside Iran in his career.

Motif of Saeed Rafiee Monfared's works is reality figures. Figures in familiar atmosphere but in unfamiliar situation became surprising. As it is known, woman in his works has significant presence and in majority of cases critical insight surges from the image of these women. In any case, women are the half of human beings' population and in any case, any painter that involved with the subject of human being paints the women too. However, what is considered in this discussion is a specific view that places women at the particular attention. In his works, Women are portraying exactly with this intention.

In the drawings of the "Risk" series, women are painted in the minimalist space and alongside the text or strips in which the word danger is seen in English or Persian. In these works, women are at a "dangerous" situation. In another word, this danger is related to the current atmosphere of society in Iran, and these women are also present in this society and are covered in the social customs of this society.

A woman standing on a stool and is wearing a floral chador was tied with a rope and in front of her, there is a brown wall a small strip of the blue sky. The woman in the painting has a half face in the frame and is holding a small mirror and is wearing lipstick. She is wearing makeup in an outer space and on a stool. All this description directs the audience's attention to the hidden danger in the heart of the image. It's as if this kind of actuality in this unknown while familiar place is a dangerous fact. In fact, this is the same and women in today Iranian society, with any reason, do not enjoy a situation in which they can do their personal works (makeup), although 
they observe the appearance (chador) that has been accepted to them (Figure 4).

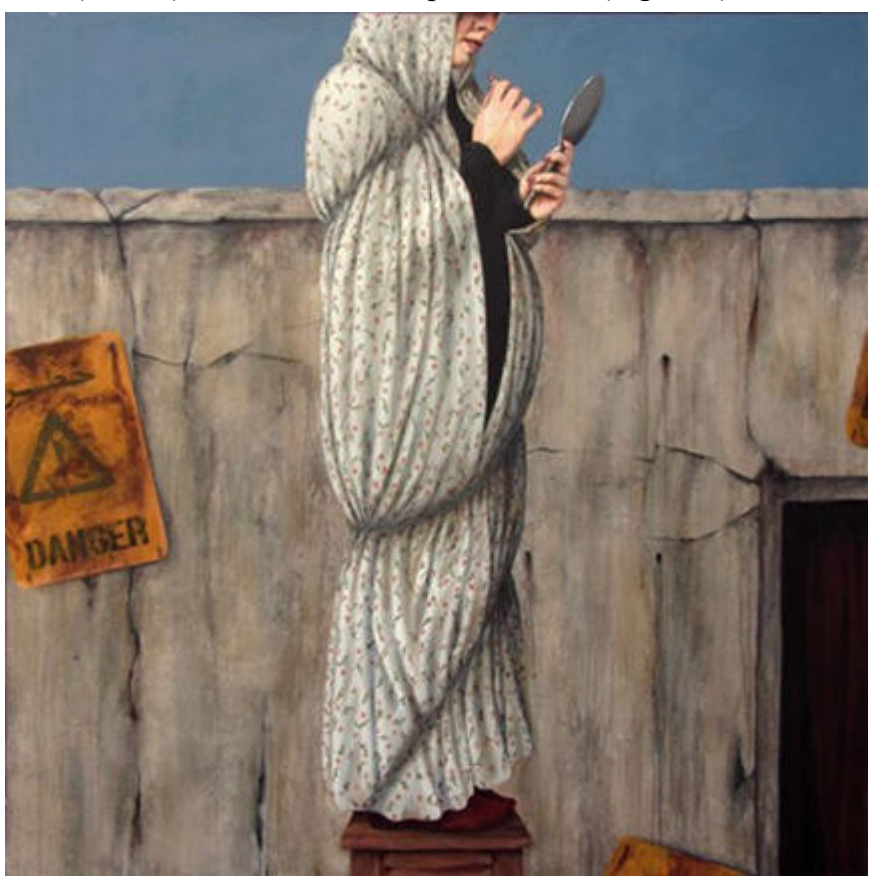

Figure 4. Untitled, from the Mokhatereh (danger) series, oil paint on canvas, 2013

Rafiee Monfared in his works often uses signs and symbols. In the works of narrative painting that are followed by a story or message, such cases are more visible. These signs are sometimes seen symbolic and encoded, and sometimes are seen in pictorial expression and artistic contraption.

In one of his works, lemons hanging from the top of the cadre and can be seen in interior environment of a room. In this environment, reddish-brown curtain is also depicted that covered major part of the cadre. The small part of this curtain is also visible on the left and bottom of the cadre. The background colour in this image is bluegray, but what matters is the figure of a child with doll in her arm and eyes covered behind the hand. This baby girl is portrayed in a brown dress.

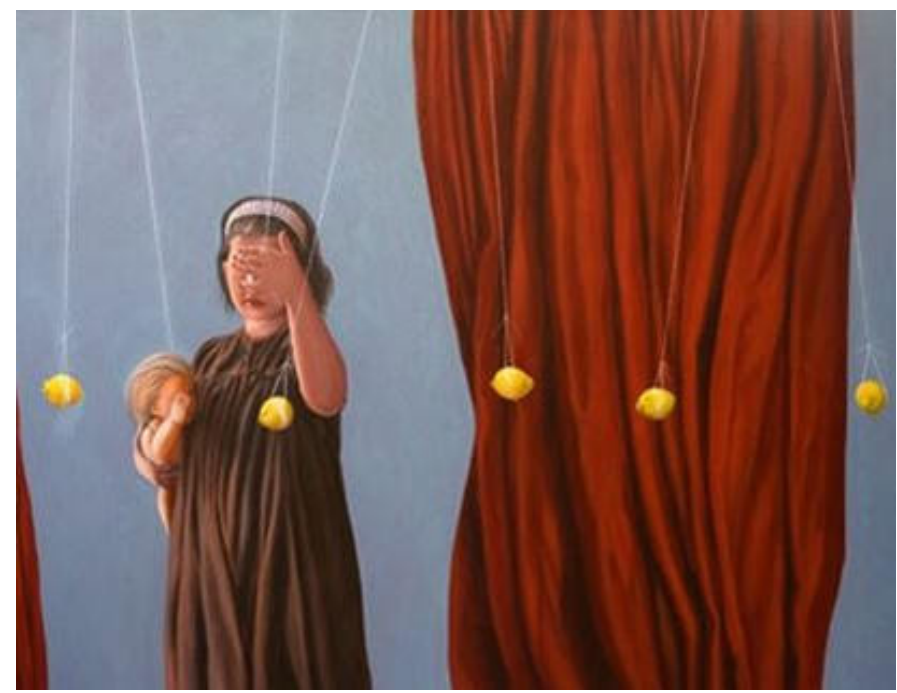

Figure (5) untitled, Saeed Rafiee Monfared's work, Oil Paint on Canvas, 2010

Symbolic language in this image is the use of fruit that is the sign of physical puberty of women. Lemon has been used in literature and painting as a symbol of this case. In addition to the matter, he used threads that came 
in from the top of the cadre or sky and connected to anything that is also symbolically used. These threads refer to the puppet's threads. The baby girl that still playing with her doll will suddenly be involved with the physical and bodily issues of puberty and menstruation. The red colour complexion represents the same issue (Figure5) .

In another Rafiee Monfared's work which is a painting from this series, the presence of a middle-aged woman in an imaginary atmosphere attracts the attention. The woman who is actually naked is covered with a full-length dress up to the top of her breast. The background of the image is again blue, but in its cool atmosphere, there are bare autumn trees. In this image, some hanging threads control her arms and a piece of string is in front of her face. Red curtains around the frame are also leaving the space. In this image, all of these signs or the selected symbolic language illustrate the importance of women's issues in the painter's minds from the onset of her physical maturity to her menopause (Figure 6).

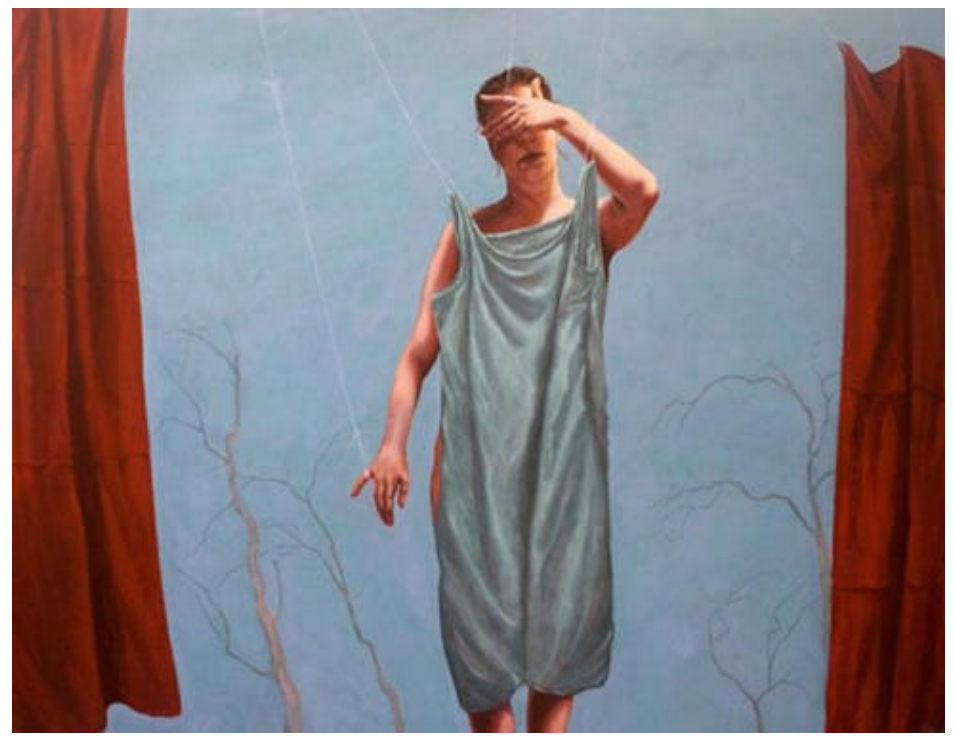

Figure 6. Untitled, the work of Saeed Rafiee Monfared, Oil paint on Canvas, 2010

Perhaps in today's society everyone who claims to have free thinking has to think of women and their rights. This person, in every position, resorting this thought, considers himself as one of the main supporters of women's rights, although he does not express his approach. This is true about him.

As a painter and thinker in the current Iranian society, he has to deal with women's cases. Of course, instinctive desire, appeal and sexual attraction in the sense of its acceptance can also be effective. In any case, Rafiee Monfared at the position of a man looking at the woman's issue proposes the same attitude. In his works, women's issues are raising and often he does not offer solution for them, which the mission of painting does not except this.

\subsection{Zeinab Movahhed}

Zeinab Movahhed was born in 1981 in Tehran and received her education in the field of painting from the Islamic Azad University of Tehran Centre in 2007. She also obtained his master's degree in the same field in 2011 from the same university. She is the associate member of Iranian Painters Association and has experience of numerous group and individual exhibitions both inside and outside Iran in her artistic background (arthibition.net).

She with her clear effort in the realm of realism combines decorative and figurative elements to achieve her goal. In her works, she focuses on the issue of women, but what it apparent is that she involved in surface and upper layer of this issue. In the current society, the case is not about women's reading or writing. In her works, only one person is shown as a woman in different situations, which of course is a portrait of her without face. This person sometimes shows herself in the anatomy of a housewife and sometimes as a marriageable girl and in some cases, it is a traceless and seducer figure.

The women in Movahhed's paintings, in every form that are seen, have a very feminine configuration, and appear in today's society in their modern clothes and make up. Choosing topics such as a woman in the kitchen 
or in general with home appliances or dirty clothes, dishwashing gloves, and iron, and so on is exotic in Iranian community. Of course, such themes have different audiences since there are a great number of such people. A woman with polished nails and floral apron who is sitting on a chair with an artificial status and in front of her, the kitchen gloves are hung creates an image that addresses a wide range of ordinary people, although for wise people, it is a cheap picture.

In some of her paintings, a woman or a girl (her own picture) is drown with folk tendencies with decorative motifs or elements such as butterflies, golden colours, geometric decorations, imprint fabric, and more. It also adds to its visual appeal. These images are presented without any criticism and merely for the pleasure of some individuals, especially people of the community, to attribute a feminist and gender-focused critique to her. In most of these images, the sexual attraction of the image and the woman's body is used. The woman's status and her body, clothes and acts show a deceptive image.

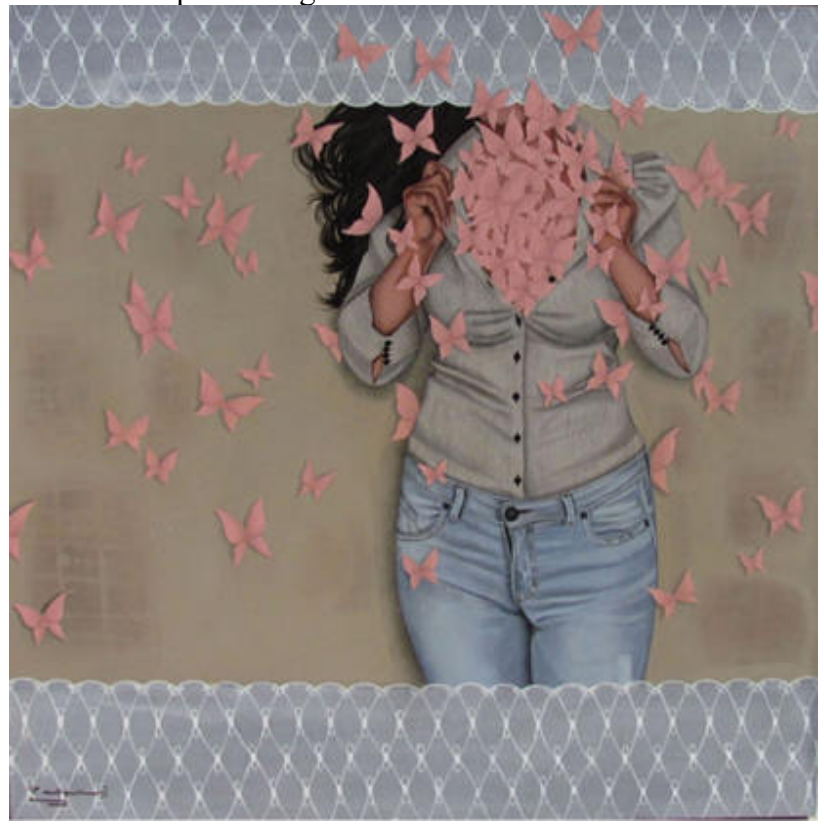

Figure 7. Love oneself, the work of Zaynab Movahhed, Acrylic and pencil on a120 by $120 \mathrm{~cm}$ canvas, 2013

Like most of the painters who deal with narration, Zainab Movahhed's works have symbols and signs. By choosing the name of "clothes hanging rope" for her collection, this issue attracts more attention. She has used visual symbols such as crows, butterflies, books or newspapers, floral or lattice fabrics, dolls, etc. to invite her audiences to understand the concept of her paintings ( Figure 7).

In one of her works, the main figure is at the centre of attention and it is surrounded by crows. The background of the picture is in green and in the image, the face is covered by the woman's hair. A lace fabric is also diagonally positioned above the top of the image. The two rows of black ropes are drawn in the middle of the picture from right to left, and the white crow is sitting on one of them. Five crows are drawn under a white crow, and two crows, one of whose body is outside the frame, is on the left side of the image. What is clear is that the figure stands in front of the wall and there is a shadow of it behind and on the wall. The figure that has been depicted in modern clothes (jeans and so on) has a book with a black cover (Figure 8). 


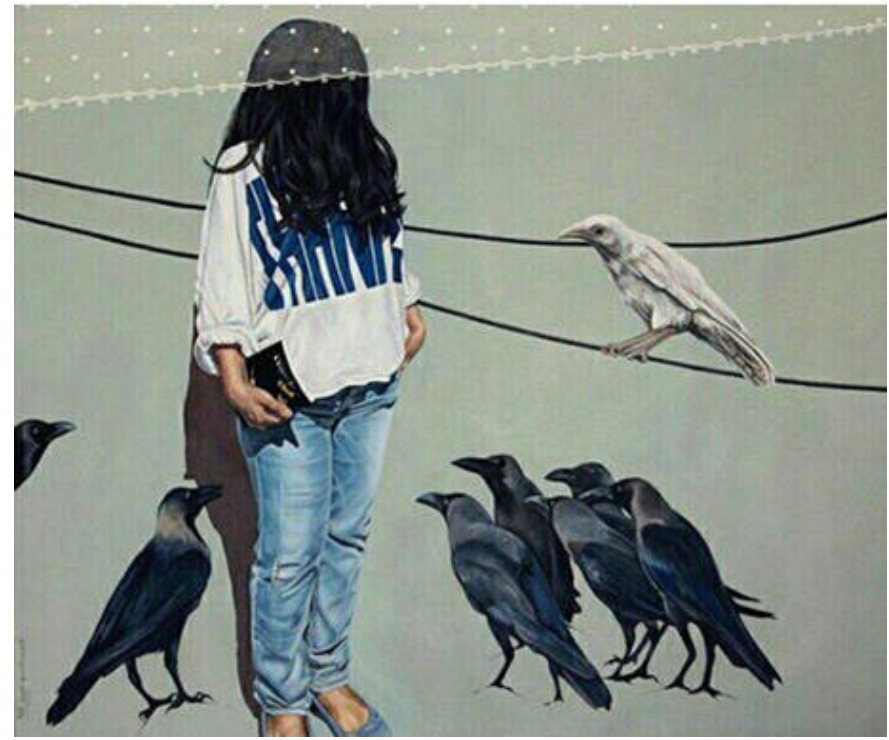

Figure 8 Untitled, Zaynab Movahhed's work, Akrelik on Canvas

Covering the face with mask in the works of Zeinab Movahhed adds another point in the overall concept of her paintings. This woman or girl is depicted as an example of the women's community and represents a particular group of them, not a certain individual who, at any moment, displays himself in a situation.

In her paintings, picture of a girl representing some of the women in this community is shown with feminine concerns and desires. A feminine world without any male and violence is shown her works. In one of her works, a girl hiding behind a lace fabric is holding a doll, and through an unclear window, the light is shining from her behind and illuminates a part of the floral fabric. Maybe this girl is waiting for someone who comes and seeing him, the girl says goodbye to this very girl-oriented world, dolls and floral fabrics (Figure 9).

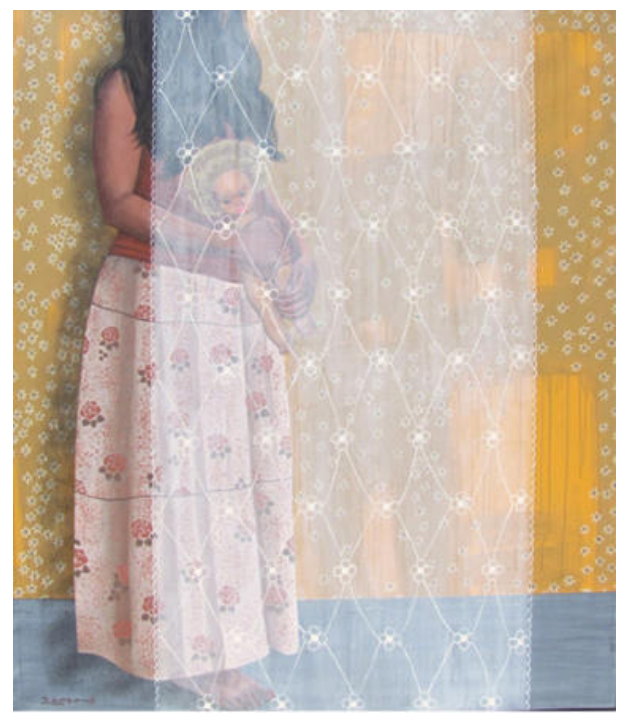

Figure (9) Untitled, the work of Zaynab Movahhed, Acrylic on a 120 by $150 \mathrm{~cm}$ Canvas, , 2012

With this kind of look, her works are very female-oriented which can cause a critical look to these works. However, what is certain is that, she has separated women or better to say, her figurative woman, from a crowded human world and has given her a self-wanted isolation in which she can live with her sweet fantasies. Movahhed's world is not without men, but a world without people, an imaginary world for a girl who is lost in 
her dream.

\section{Conclusion}

In the Iranian society, there is a relatively different understanding of women and their presence in the community. As a result, due to Iranian-Islamic culture, different social classes have got used to and accustomed to it. Since artists with different motives pay attention to hidden social realities, in some cases they have been involved in this issue and have created their own works with different approaches. Using visual forms, painters have created different concepts of women's image which are usually accompanied by criticism or raising fundamental questions. In the same vein, with feminist analysis of paintings, it is possible to achieve acceptable results.

In relation to the position of women in the works of the discussed painters, its importance should be noted in the first place. In another word, women are the most prominent subjects in Iran's contemporary painting. This presence is also of great importance in the works of the discussed artists. Often, the images of women, whether directly or indirectly, play a critical role in the artwork of artists, although in some cases it also has a hidden form of sexism.

In the discussed works, what reveals itself clearly is that each artist, depending on the way of looking, thinking and worldview, has entered into an issue related to women who are fundamentally different. In the works of Shideh Tami, we are faced with a feminine look at the aggravated and often deformed portraits that arise from women's emotional grieve about their environment and society. Tami does not go straight to a feminist subject, but as she is a woman, a woman-oriented look is also observed in her works. In her works, women's issues or gender issues are not presented at all, and her drawings are mostly emotional and are not protesting the situations of women in the society. She draws the women of today's Iranian society or better to say women from her period. In Tami's works, the fears and violence or the behavior of the community towards these women appear entirely from the inner and subconscious path while an aware critic and viewer can also determine the feminist roots of these images. Shideh Tami, as a female artist, goes to portraits of women and sometimes men in the community, which should not be ignored.

Saeed Rafiee Monfared represents women not as a different and separate entity but as one of her constituent parts. In his work, a woman is a part of the foundation of the community that is threatened and exposed to various harm. Despite the fact that the woman's image in Rafiee Monfared's works have a realistic structure, and present a healthy and complete picture of women, but with techniques such as covering women's faces or bodies by technical and visual elements, he avoids paying attention to their sex. In Rafiee Monfared's works, women's figures do not have any seductive role, and quite contrary, he avoids this issue. Certainly, Rafiee Monfared's works have a critical look at the status of women in the current Iranian society, but what is clear is that his works do not suggest a way to exit from this particular situation. Most of his paintings propose questions and situations to express critical views on women's rights. Despite his avoidance from a sexism narration, Rafiee's works have sexism images that put the painter in a trap, although he avoids such a situation.

Zeinab Movahhed's works, in the first place, reveal their decorative aspects. Like Rafiee Monfared, Movahhed chooses both a representative and realistic style and makes more audiences be involved with her works. At the same time, her works can be feminist criticized since the representation of women's figures in different situations with different clothes causes this important issue. In addition, in some works, statuses and situations are given to the young women's figure are considered seductive and provocative. In Movahhed's works, women are the symbol of girls from her class who have sweet aspirations. Perhaps Movahhed's works seem to have low power in representing the real role of women in the current Iranian society. The reason is the one-dimensional and limited look of these works. By placing women in housewives' positions or giving them symbolic situations of reading and studying, Zaynab Movahhed has given more slogan-stricken and exotic conditions to her works, although she claims that she drew the passive and critical women's images. The use of decorative and popular elements, along with her realistic method, exposed her paintings to this danger.

In general, it can be said that all three painters drew women's images with a sexism theme, although the sexism look in these painters' works are seen in Zeinab Movahhed, Rafiee Monfared and Shideh Tami's works, respectively. By reviewing these three artists' works, one can say that none of them has painted with just a feminist and critical approach, and each of these painters has entered into a small part of women's issues in their works. One might think that such expectation about the painters is a bit avarice, but the presence of artists in the history of world art and Iran's art who have been directly involved in this type of critique and challenge, this claim will be intensified. However, each of them has presented a part of these issues and achieved a relative 
success.

\section{References}

1. Afshar. Nastaran. (2001). Women's Portraiture in Contemporary Painting. Master's Thesis. Islamic Azad University, Tehran Central Branch, Faculty of Arts and Architecture, Iran.

2. Alikhani Rad. Amir. (2009). Women's images in Iran and the West (second half of the twentieth century). Master's Thesis. University of Art, Faculty of Visual Arts, Iran.

3. Arbabi. Bahar. (2014). Analysis of the social reflection of women's image in Iran's painting of the eighty's decade. Master's Thesis. University of Science and Culture, Faculty of Arts and Architecture,Iran.

4. Ataee Ashtiani. Zohre. (Summer 2006). "Aesthetics in Gender Analysis of Feminism", Women's Book, Iran.

5. Bolkhari. Hassan. (Spring 2010). "Women in Art" (Spring 2010), Women's Strategic Studies, No. 47. Iran.

6. Bagheri No'parast. Khosrow. (2003). Philosophical Foundations of Feminism, Tehran: Publication of the Ministry of Science, Iran.

7. Beasley. Chris. (1999). What is feminism? An introduction to feminist theory, translated by Mohammad Reza Zomorodi; Tehran: Roshangaran publication and women's studies, Iran.

8. Crochet, Bento (1971), Aesthetic General, Translator Fo'ad Rouhani, Tehran, Translating and Publishing Agency, Iran.

9. Dekel. Tal (2013). Gendered: Art and feminist theory, Cambridge scholars Pub, UK.

10. Fashengchi. Mina. (July 2005), "The Effect of Feminism on Visual Arts", Tandis pub, No.53, Iran.

11. Freedman, E. B. (2007). No Turning Back the History of Feminism and the Future of Women, The Random House Publishing Group, New York.

12. Gaze. Delia. (1997). Dictionary of Women Artists, Fitzory Dearborn Pub, London \& Chicago.

14. Korsmeyer. Carolyn. (2004). Feminism and Aesthetics, Rutledge Pub, London and New York.

15. Kowvaleski Wallace. Elizabeth. (1996). Encyclopedia of Feminist Literary Theory, Rutledge Pub, London and New York.

16. Miller. William Ian. The Anatomy of Disgust (Cambridge, MA: Harvard University Press, 1997): xii.

17. Robinson. Hilary. (2001). Feminism Art Theory, Black well Pub, USA.

18. Sajjadi. Seyyed Mehdi. (2005). Women's Books Quarterly, Eighth year, No. 29, Iran.

19. Samiazar. Alireza. (2007). "Feminist Art, the Birth of Women's Thoughts", Women, No. 143, Iran.

20. Zolberg. Verza. (2008). What is art? What is the sociology of art? In: Principles of Sociology of Art, translation and compilation by Ali Ramin, Tehran, Nei Pub, Iran. 